\title{
A Systematic Review to Explore the Factors Related to Parent to Child Transmission of HIV, Survival and Treatment Provision of Children with HIV in India
}

\author{
Arvind Kumar Singh, Partha Haldar*, Sanjay Kumar Rai, Shashi Kant \\ Centre for Community Medicine, All India Institute of Medical Sciences, New Delhi, India \\ Email: ${ }^{*}$ drparthohaldar@gmail.com
}

Received 20 August 2015; accepted 22 September 2015; published 25 September 2015

Copyright (C) 2015 by authors and Scientific Research Publishing Inc.

This work is licensed under the Creative Commons Attribution International License (CC BY).

http://creativecommons.org/licenses/by/4.0/

(c) (i) Open Access

\section{Abstract}

Introduction: There are a multitude of factors that impact the transmission of HIV from parent to child and the subsequent survival of infected children. Changing dynamics in HIV transmission have led to an increase in the number of children living with HIV in India. This review synthesizes the evidence related to transmission of HIV to children, survival and treatment provision among children living with HIV. Methods: A systematic search was conducted in MEDLINE, IndMed, Web of Science, Google Scholar and major journals related to HIV/AIDS to identify relevant studies published between 1992 and 2015. Inclusion criteria included studies related to parent to child transmission of HIV, treatment of children living with HIV and survival of children living with HIV. One of the authors reviewed the studies and extracted the data in a pre-coded extraction sheet. Results: Thirty-three studies were included in the review. HIV transmission rate from parent to Child who received nevirapine prophylaxis ranged from $2.1 \%$ to $27.3 \%$. Extended dose regimen of nevirapine prophylaxis was found to be more effective than the single dose regimen. Adherence to ART ranged from $65 \%$ to $95 \%$. Adherence varied depending upon the level of health care facility. Both social and medical factors were associated with non-adherence. CD 4 count at the time of diagnosis and delayed age at HIV diagnosis were important predictors of survival. Conclusion: Shift in policy to provide option $B$ regimen is yielding better results. If the age at diagnosis could be reduced further, it would increase the survival of children living with HIV. The program needs to increase access to the health care facilities.

${ }^{*}$ Corresponding author. 
Keywords

PPTCT ${ }^{1}$, ART, Children, India, Adherence, Prophylaxis

\section{Introduction}

The HIV program in India has evolved dramatically over the last decade. Preventive and behavior change strategies, along with a scaled-up program for coverage of antiretroviral therapy (ART), have led to a nearly $50 \%$ decrease in the estimated number of new HIV infections in India - from 250,000 in 2001 to 120,000 in 2012 [1].

The HIV epidemic in India is concentrated in nature and heterogeneous in distribution [2]. Heterosexual transmission remains the most important driver for HIV transmission among the general population whereas intravenous drug use, men having sex with men, and migrant population are a high risk population [2]. The prevalence of HIV among antenatal clinic attendees had shown a declining trend. Adult HIV prevalence in India had declined to an estimated $0.31 \%(0.25 \%-0.39 \%)$ in 2009 against $0.36 \%(0.29 \%-0.45 \%)$ in 2006 . Penetration of the epidemic in the general population has resulted in an increased burden of HIV among children in recent years [3]. Seven percent of the total HIV cases were among children aged less than 14 years [1]. Estimates suggest 14,500 incident HIV infections annually among children, assuming a vertical transmission rate of 30\% [1]. UNAIDS has reported an increase in the number of children living with HIV (CLHIV) between 2001 and 2011 [4]. Evidence suggests an overall risk of parent to child transmission through breast feeding up to $18-24$ month of age, in the absence of any intervention, to be $30 \%-45 \%$ [5]. However, interventions for prevention of parent to child transmission have been significantly scaled up in the country, which has led to a lower parent to child HIV transmission rate.

Since 2012, the policy of single dose nevirapine prophylaxis has changed to a more effective multi-drug regimen [3]. The current strategy is to provide life-long ART to pregnant women (Option B plus) [5]. Identification of HIV exposed fetuses during the antenatal period is the cornerstone to enhancing the subsequent survival of HIV infected children. Apart from antenatal prophylaxis, a number of other factors, such as feeding practices and type of delivery, also play a role in transmission of HIV infection to the child. Survival of HIV infected children depends on various factors like early infant diagnosis, early entry into care, access to care, and socio-demographic characteristics. Enhancement of care, support and treatment in the form of provision and universal roll-out of anti-retroviral therapy (ART) have also improved the survival of CLHIV [5]. Higher access to ART services has decreased the mortality rate in CLHIV. The estimated 260,000 children who died from AIDS-related illnesses in 2009 were 19\% fewer than the estimated 320,000 who died in 2004 [4]. However, adherence to treatment is an important challenge in prolonging the survival of CLHIV. Thus, there are a multitude of factors that impact the transmission of HIV from parent to child, and the subsequent survival of infected children. Most of the literature published from India has an inadequate sample size and have not been conducted in a sufficiently robust manner. Many studies have relied on programmatic data, whose quality is uncertain. Thus, it is necessary to conduct a systematic review to synthesize the existing literature on parent to child HIV transmission, survival and treatment of CLHIV. The only available systematic review published from India has not focused on these aspects, but has mainly presented findings on utilization and access to prevention of parent to child transmission (PPTCT) services [6].

In this paper we present findings from a systematic review of the literature published from India regarding parent to child transmission of HIV and treatment and survival of CLHIV.

\section{Methods}

\subsection{Literature Search Strategy}

We conducted a comprehensive search to identify all relevant studies related to parent to child transmission of HIV, treatment and survival of CLHIV (Box 1). We searched the following databases: Medline, Pubmed, IndMED, and used search engines like Web of Science and Google Scholar. To locate additional studies and reports, we screened the table of contents of journals that publish studies related to HIV/AIDS and scanned the websites of national and international organizations like National AIDS Control Organization (NACO), World ${ }^{1}$ PPTCT: Prevention of Parent To Child Transmission. 
Health Organization (WHO), United States Agency for International Development (USAID), and United Nations Program on HIV/AIDS(UNAIDS). We also searched the reference lists of articles included in the systematic review.

\subsection{Study Selection}

We conducted the search using three sets of key words. 1) Prevention of Parent to Child Transmission OR PPTCT, Parent to Child Transmission OR MTCT, Antenatal prophylaxis, Nevirapine prophylaxis, Option B regimen, Type of delivery, Delivery, Caesarean, Infant feeding, Mixed Feeding, Replacement feeding, Sero-discordance, AND India; 2) Survival, Early Infant Diagnosis, Access to care, CD 4 count, Adherence, AND India AND HIV and Children OR Pediatric; 3) Anti-retro Viral Therapy OR ART, Adherence, Effectiveness, Efficacy, Survival, AND India AND Children OR Pediatric. The search was restricted to studies published between 1992 and 2015. All studies published in English or with a detailed summary in English were included in the review. The search was conducted in January 2015.

\subsection{Data Extraction}

We screened the titles of all the search outputs, and excluded studies that were not found to be relevant. Abstracts of all the titles found to be relevant to the present review were screened, and those that met in the inclusion criteria, as given in Box 1, were included. We exported the search results to EndNote reference manager software. A structured data extraction sheet was used, based on the Cochrane data extraction sheet and the New Castle Ottawa scale. Quality assessment for randomized control trials was done using a five-point scale, namely the process of randomization, treatment allocation, baseline comparability, blinding and drop-out rate. However, we did not screen or exclude studies based on methodological quality as the purview of this review was exploration rather than estimation. Data extraction was done under the following heads: domain and sub-domain of the study, study identifier i.e. last name of author, year of study and publication, PubMed ID, study characteristics (study design, study setting, objective, sample size, and inclusion and exclusion criteria), participant characteristics for studies related to survival and treatment (sex wise, mean age, and age group), objective, exposure, outcome and important findings, drop-out rate and adjustment for confounders.

\section{Results}

\subsection{Search Results and Thematic Categorization}

We retrieved a total of 842 titles from the search term alone or in various combinations. Of these, 686 were not found to be relevant to the present review or were duplicate searches - i.e. the same title retrieved from different

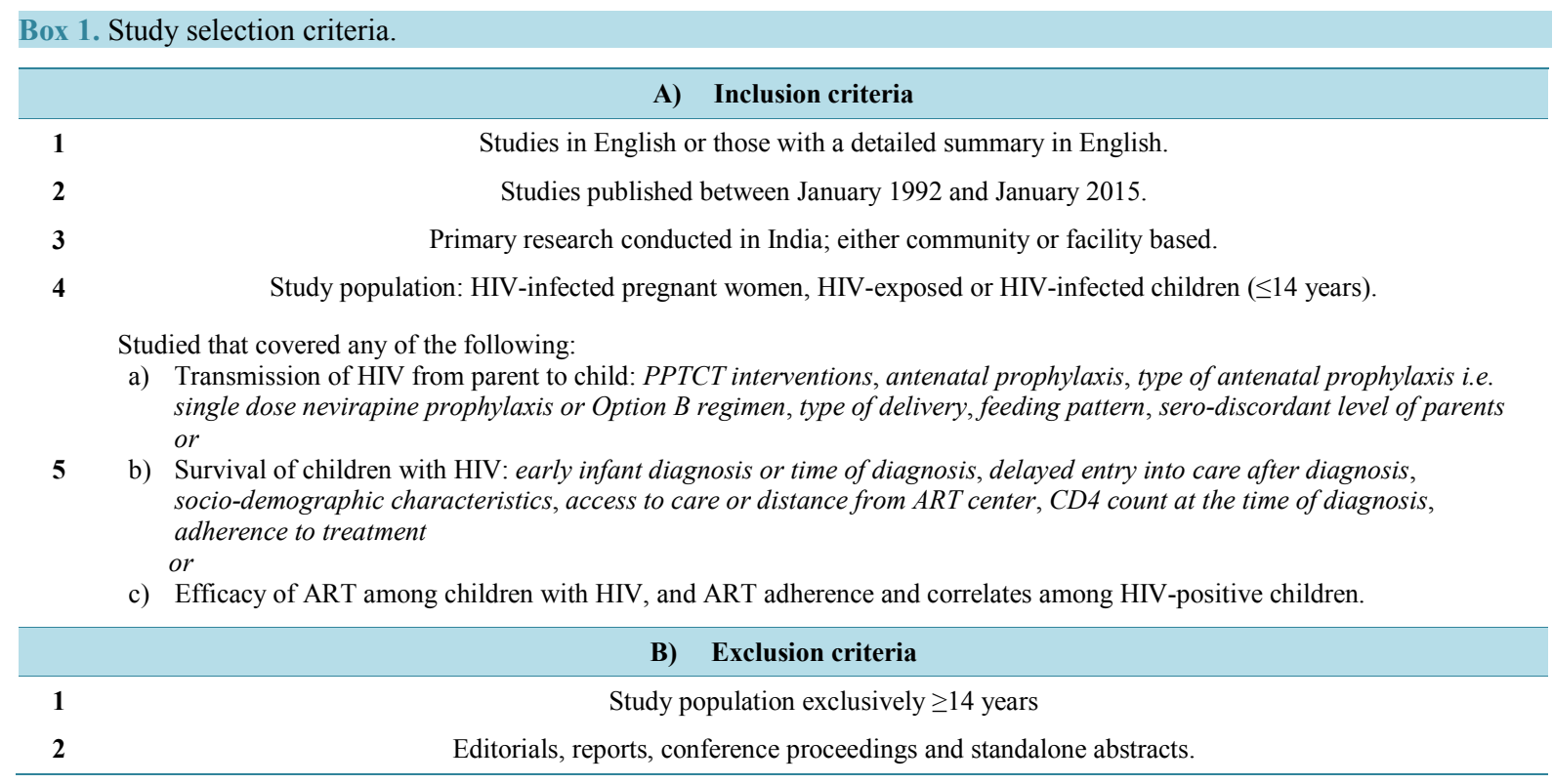


sets of keywords. The abstract and full texts of the remaining 156 studies were screened, of which 33 met the inclusion criteria. These 33 selected studies were thematically grouped into three categories: i.e. studies related to parent to child transmission of HIV (19 studies), treatment of children living with HIV (11 studies), and survival of children living with HIV (3 studies). The results of the literature search and thematic categorization of studies are presented in Figure 1.

\subsection{Salient Characteristics of the Selected Studies}

All the studies included in the review were conducted after 2000, and were health facility-based studies. Most $(88 \%)$ were conducted in urban public health facilities. While around half were conducted in the high HIV prevalence states of Andhra Pradesh, Tamil Nadu and Maharashtra, 20\% were conducted in West Bengal and 10\% in Gujarat. Only three studies were conducted in the states of north India. In all, 28 studies were interventional or observational follow-up studies, 2 were cross-sectional studies and 3 were retrospective cohort studies (Table 1).

\subsection{Parent to Child Transmission of HIV}

Most studies explored the effectiveness of single dose nevirapine prophylaxis, and were conducted in a public health facility in southern India. All except two studies had a sample size of between 30 and 1890 HIV infected pregnant women.

The HIV sero-positivity rate among antenatal women ranged from $0.17 \%$ to $0.56 \%$ [13] [15] [22]. HIV transmission from HIV-infected parent to child who received nevirapine prophylaxis ranged from $2.1 \%$ to

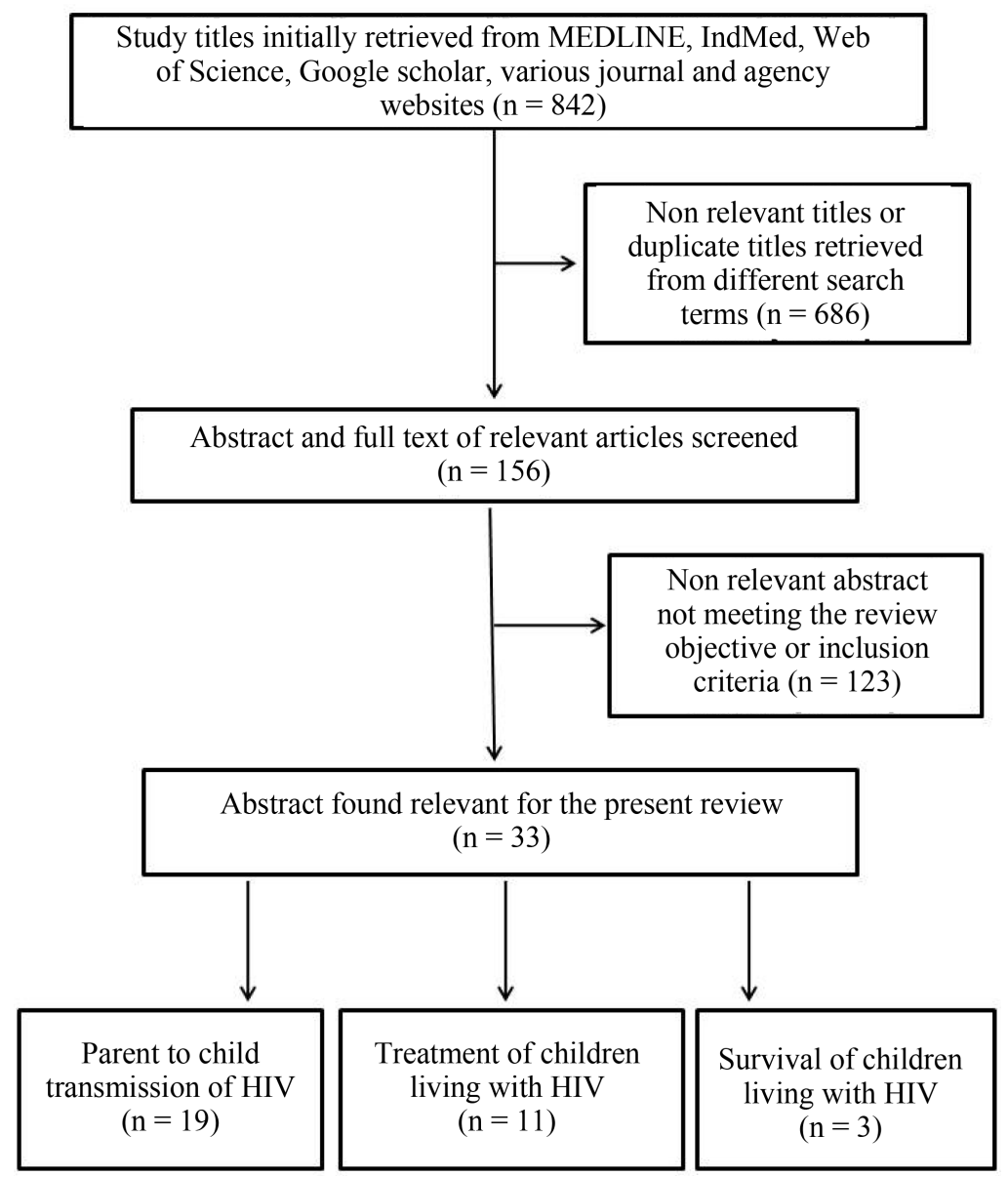

Figure 1. Flow diagram of study search and thematic categorization of selected studies. 
Table 1. Key findings of studies included in the review.

\begin{tabular}{|c|c|c|c|c|}
\hline S. No. & $\begin{array}{c}\text { Author } \\
\text { (Year) }\end{array}$ & $\begin{array}{c}\text { Study site } \\
\text { (setting) }\end{array}$ & $\begin{array}{l}\text { Sample } \\
\text { size }\end{array}$ & Key findings \\
\hline
\end{tabular}

\section{Parent to child transmission of HIV}

\begin{tabular}{|c|c|c|}
\hline 1 & $\begin{array}{l}\text { Alvarez Uria } \\
\text { G. (2012) [7] }\end{array}$ & $\begin{array}{l}\text { Andhra Pradesh } \\
\text { (Rural) }\end{array}$ \\
\hline 2 & $\begin{array}{c}\text { Arora et al. } \\
\text { (2014) [8] }\end{array}$ & $\begin{array}{l}\text { Maharashtra } \\
\text { (Urban) }\end{array}$ \\
\hline 3 & $\begin{array}{l}\text { Goswami et al. } \\
\text { (2011) [9] }\end{array}$ & $\begin{array}{l}\text { West Bengal } \\
\text { (Urban) }\end{array}$ \\
\hline 4 & $\begin{array}{l}\text { Gupta et al. } \\
\text { (2013) [10] }\end{array}$ & $\begin{array}{l}\text { Maharashtra } \\
\quad(\mathrm{NM})\end{array}$ \\
\hline 5 & $\begin{array}{l}\text { Gupta } \text { et al. } \\
\text { (2007) [11] }\end{array}$ & $\begin{array}{l}\text { Maharashtra } \\
\text { (Urban) }\end{array}$ \\
\hline 6 & $\begin{array}{l}\text { Jain et al. } \\
\text { (2011) [12] }\end{array}$ & $\begin{array}{l}\text { Gujarat } \\
\text { (Urban) }\end{array}$ \\
\hline 7 & $\begin{array}{l}\text { Joshi et al. } \\
(2010) \text { [13] }\end{array}$ & $\begin{array}{l}\text { Gujarat } \\
\text { (Urban) }\end{array}$ \\
\hline 8 & $\begin{array}{l}\text { Joshi et al. } \\
\text { (2011) [14] }\end{array}$ & $\begin{array}{l}\text { Gujarat } \\
\text { (Urban) }\end{array}$ \\
\hline 9 & $\begin{array}{l}\text { Mandal et al. } \\
\text { (2010) [15] }\end{array}$ & $\begin{array}{l}\text { West Bengal } \\
\text { (Rural) }\end{array}$ \\
\hline 10 & $\begin{array}{l}\text { Merchant et al. } \\
\text { (2001) [16] }\end{array}$ & $\begin{array}{l}\text { West Bengal } \\
\text { (Urban) }\end{array}$ \\
\hline 11 & $\begin{array}{l}\text { Omen et al. } \\
\text { (2011) [17] }\end{array}$ & $\begin{array}{l}\text { West Bengal } \\
\text { (Urban) }\end{array}$ \\
\hline 12 & $\begin{array}{l}\text { Read et al. } \\
(2010)[18]\end{array}$ & $\begin{array}{l}\text { Tamil Nadu } \\
\text { (Rural) }\end{array}$ \\
\hline 13 & $\begin{array}{l}\text { Seth A. et al. } \\
\text { (2012) [19] }\end{array}$ & $\begin{array}{l}\text { North India } \\
\text { (Urban) }\end{array}$ \\
\hline 14 & $\begin{array}{l}\text { Shah et al. } \\
\text { (2006) [20] }\end{array}$ & $\begin{array}{l}\text { Maharashtra } \\
\text { (Urban) }\end{array}$ \\
\hline
\end{tabular}

SWEN study 15 team (2008) [21]

Chaudhary et al. (2010) [22]

Ahir et al. (2013) [23]

Gupta et al. (2011) [24]
Maharashtra (Urban)

West Bengal (Urban)

Maharashtra (Urban)

Maharashtra (Urban)
The overall HIV transmission rate from parent to child was $3.7 \%$. The cumulative 523 12-month mortality was $9.6 \%$ for formula-fed infants versus $0.68 \%$ for breastfed infants.

30 The overall transmission rate to infant till six weeks of age was $20 \%$.

248 women were detected positive for HIV. Only 46 live births were tested for HIV and the transmission rate was $2.1 \%(1 / 46)$.

18 women tested HIV positive, leading to a transmission rate of $8.3 \%$. The 217 transmission rate among HIV infected parents who followed the PPTCT protocol was $5.2 \%$ vs $17.5 \%$ among those who did not.

Of the 41 infants who received nevirapine prophylaxis, the overall transmission rate 41 up to the age of one year was $8 \%$. The transmission rate in exclusively formula fed infants was $3.1 \%(1 / 31)$ vs $30 \%(3 / 10)$ in the mixed feeding group.

326 The transmission rate among those who received ARV prophylaxis was $5.2 \%$ (14/270) vs $41.1 \%(23 / 56)$ among those who did not.

The HIV transmission rate among infants delivered through cesarean section was $2.9 \%(1 / 35)$ and $4.1 \%(2 / 49)$ for vaginal delivery at 18 months of age. With respect to feeding practice the transmission rate was $25 \%$ for those in the mixed feeding group, $2.4 \%$ for those exclusively breast fed and $0 \%$ for those exclusively formula fed.

81 Among infants who received single dose nevirapine prophylaxis and tested for HIV at age one year, the transmission rate was $3.1 \% .1 / 32$ ).

Among parent child pair who received nevirapine with exclusive formula feeding, and 19794 tested at at 18 months of age, the transmission rate was $15.0 \%$ versus $57.2 \%$ in absence of both the interventions.

Among children who received single dose nevirapine prophylaxis and tested at 18 92 months of age, the transmission rate was $5.9 \%(4 / 68)$ vs $24.0 \%(55 / 229)$ among those who did not receive prophylaxis.

The HIV transmission rate in the single dose prophylaxis group (10.4\%) was higher than in the extended dose regimen group $(8.9 \%)$. But, the difference was not

1890 statistically significant [risk ratio: $0.87 \%, 95 \%$ confidence interval (CI): $0.65-1.15$ ] Cumulative mortality in the extended dose regimen group was also significantly less (risk ratio $=0.53,95 \% \mathrm{CI} 0.32,0.85$ ) than in the single dose regimen group

780 The parent to child HIV-1 transmission rate of was $6.5 \%$ (95\% CI: $1.4 \%-17.9 \%)$.

162 The HIV transmission rate was $14.8 \%$.

The HIV transmission rate for infants delivered through cesarean section was $1.1 \%$ $(2 / 174)$. And for vaginal delivery it was $2.1 \%(1 / 48)$. Thus, elective cesarean section was not statistically better as compared to vaginal delivery $(\mathrm{p}=0.8696)$ in presence of ART during pregnancy and absolute formula feeding during first six months.

The HIV transmission rate at 6 months of age among HIV exposed infant who received single dose nevirapine prophylaxis was $9.6 \%(87 / 901)$ whereas it was $6.3 \%$ 770 (62/986) among those who received extended dose regimen. relative risk of acquiring HIV in infants was $0.80(\mathrm{RR}=0.80,95 \%$ C.I. $0.58-1.10)$ when given extended dose regimen as compared to a single dose regimen

47506 Of the 11 children who had received single dose nevirapine prophylaxis, three (27.3\%) were HIV positive at 18 months of age.

At the end of 18 months two of 58 children (3.5\%) were HIV positive whose parents were on nevirapine prophylaxis.

Of 33 parents with TB, $10(30 \%)$ transmitted HIV to their infants compared to 87 of 750 parents without TB $(12 \%)$ 


\section{Continued}

\begin{tabular}{|c|c|c|c|c|}
\hline 1 & $\begin{array}{l}\text { Alvarez Uria } \\
\text { G. et al. }(2013) \\
\quad[25]\end{array}$ & $\begin{array}{l}\text { Andhra Pradesh } \\
\quad \text { (Rural) }\end{array}$ & 247 & $\begin{array}{l}\text { The cumulative incidence of attrition was } 12.6 \% \text { ( } 95 \% \text { confidence interval, } 8.7-17.3) \\
\text { after five years of follow-up. Children who belong to scheduled tribes had a higher } \\
\text { risk of delayed ART initiation and LTFU. Orphan children had a higher risk of } \\
\text { delayed ART initiation and mortality. }\end{array}$ \\
\hline 2 & $\begin{array}{l}\text { Alvarez Uria } \\
\text { G. et al. }(2014) \\
\quad[26]\end{array}$ & $\begin{array}{l}\text { Andhra Pradesh } \\
\quad \text { (Rural) }\end{array}$ & 282 & $\begin{array}{l}\text { The cumulative incidence of attrition (mortality and LTFU) was } 15.6 \% \text { at five years, } \\
\text { and the attrition rate was higher during the first year after enrolment in care. }\end{array}$ \\
\hline 3 & $\begin{array}{l}\text { Banerjee et al. } \\
\text { (2010) [27] }\end{array}$ & $\begin{array}{l}\text { West Bengal } \\
\text { (NM) }\end{array}$ & 180 & $\begin{array}{l}\text { Median duration of survival from date of diagnosis was } 15.1 \text { years. Those who } \\
\text { received HAART survived significantly longer. }\end{array}$ \\
\hline 4 & $\begin{array}{l}\text { Bhattacharya et } \\
\text { al. }(2011)[28]\end{array}$ & $\begin{array}{c}\text { Delhi } \\
\text { (Urban) }\end{array}$ & 90 & $\begin{array}{l}\text { Mean adherence was } 91.4 \% \text {. Adherence was low }(<95 \%) \text { in } 31(34.4 \%) \text { patients. On } \\
\text { multivariate logistic regression analysis, increasing time since ART initiation, low } \\
\text { caregiver educational status, orphan hood, efavirenz-based ART regimens and female } \\
\text { gender were associated with lower adherence. }\end{array}$ \\
\hline 5 & $\begin{array}{l}\text { Bhattacharya et } \\
\text { al. (2012) [29] }\end{array}$ & NA & 87 & $\begin{array}{l}\text { The outcome of ART in terms of survival was not affected by the orphan status. } \\
\text { Improvement in nutritional parameters and CD4 count was comparable in } \\
\text { both the groups. }\end{array}$ \\
\hline 6 & $\begin{array}{l}\text { Chaudhary et } \\
\text { al. (2012) [30] }\end{array}$ & $\begin{array}{c}\text { Delhi } \\
\text { (Urban) }\end{array}$ & 130 & $\begin{array}{l}\text { Following ART, a reduction in wasting was noted in } 75.0 \% \text { of children } \leq 5 \text { years of } \\
\text { age, whereas only } 44.4 \% \text { of underweight children }>5 \text { years of age showed an } \\
\text { improvement after therapy. }\end{array}$ \\
\hline 8 & $\begin{array}{l}\text { Seth A. et al. } \\
(2014)[31]\end{array}$ & $\begin{array}{l}\text { Kolkata } \\
\text { (Urban) }\end{array}$ & 106 & $\begin{array}{l}\text { Median duration of ART was } 25 \text { (IQR } 16-35) \text { months. The desired adherence level } \\
\text { of }>95 \% \text { during six months of review assessed by pill count was achieved in } 95.3 \% \\
\text { children. The } 3 \text {-day recall method yielded }>95 \% \text { adherence in } 99 \% \text { children } \\
(p \leq 0.001) \text {. }\end{array}$ \\
\hline 9 & $\begin{array}{l}\text { Violari et al. } \\
(2012)[32]\end{array}$ & $\begin{array}{l}\text { Tamil Nadu } \\
\qquad(\mathrm{NM})\end{array}$ & 288 & $\begin{array}{l}\text { The median percentage of CD } 4+\mathrm{T} \text { cells was } 15 \% \text {. The percentage of children who } \\
\text { reached the primary end point was significantly higher in the nevirapine group than in } \\
\text { the ritonavir-boosted lopinavir group }(40.8 \% \text { vs. } 19.3 \% ; \mathrm{p}<0.001) \text {. The time to a } \\
\text { protocol-defined toxicity end point was shorter in the nevirapine group ( } \mathrm{p}=0.04) \text {, as } \\
\text { was the time to death }(\mathrm{p}=0.06) \text {. }\end{array}$ \\
\hline 10 & $\begin{array}{l}\text { De et al. (2012) } \\
\text { [33] }\end{array}$ & $\begin{array}{l}\text { West Bengal } \\
\text { (Urban) }\end{array}$ & 94 & $\begin{array}{l}\text { Fifty-six percent of respondent parents and } 65.8 \% \text { of respondent children showed } \\
\text { good adherence to ART. }\end{array}$ \\
\hline 11 & $\begin{array}{l}\text { Rajashekharan } \\
\text { et al. (2009) } \\
\quad[34]\end{array}$ & $\begin{array}{l}\text { Tamil Nadu } \\
\text { (Urban) }\end{array}$ & NA & $\begin{array}{l}\text { The cumulative survival probability at } 6,12,18,24 \text { and } 30 \text { months was } 93 \%, 90 \% \text {, } \\
89.7 \%, 89.7 \% \text { and } 89.7 \% \text {, respectively. Of the children who died, about } 50 \% \text { died } \\
\text { within the first month. Nearly } 6 \% \text { of the children had adherence less than } 95 \% \text {. The } \\
\text { children who had a baseline CD } 4 \% \text { less than or equal to } 14 \% \text { had significantly } \\
(p<0.05 \text { ) higher mortality as compared to children who had } 20 \% \text { or more. }\end{array}$ \\
\hline \multicolumn{5}{|r|}{ Survival of children living with HIV } \\
\hline 1 & $\begin{array}{l}\text { Alvarez Uria } \\
\text { G. et al. }(2013) \\
\quad[36]\end{array}$ & $\begin{array}{l}\text { Andhra Pradesh } \\
\quad \text { (Rural) }\end{array}$ & 523 & $\begin{array}{l}\text { Predictors for delayed entry into care and survival were; diagnosed after knowing that } \\
\text { parent is HIV positive, age less than } 18 \text { month, alive parent, female sex, diagnosed at } \\
\text { earlier calendar years, distance at ART center }>90 \text { minutes . }\end{array}$ \\
\hline 2 & $\begin{array}{l}\text { Gupta et al. } \\
\text { (2013) [37] }\end{array}$ & $\begin{array}{c}\text { Pune } \\
\text { (Urban) }\end{array}$ & 32 & $\begin{array}{l}\text { The delayed entry into care i.e. delay in diagnosis was associated with incidence of } \\
\text { opportunistic infection and survival }\end{array}$ \\
\hline 3 & $\begin{array}{c}\text { Radhakrishnan } \\
\text { et al. (2013) } \\
{[38]}\end{array}$ & $\begin{array}{l}\text { Tamil Nadu } \\
\qquad \text { (NM) }\end{array}$ & 26 & $\begin{array}{l}\text { All } 26 \text { (13 female and } 13 \text { male) perinatally HIV infected children, born during } \\
1991-1996 \text { were healthy until } 2006 \text {. But by } 2011,18 \text { were placed in progressors group } \\
\text { with antiretroviral therapy (ART), while six remained in non progressors group and } \\
\text { two died. AIDS free median survival period (years) in long term progressors group } \\
\text { (CD4 count) of the cohort was } 10 \pm 0.66(<200 ; \mathrm{p} \leq 0.05) ; 11 \pm 0.61(200-350, \mathrm{p} \leq \\
0.05), 12 \pm 0.18(>350, \mathrm{p} \leq 0.05) \text {. Intercurrent and opportunistic infections (OIs) were } \\
\text { observed in long term progressors only. The incidence of opportunistic infections in } \\
\text { long term progressors was higher when compared to general pediatric population. }\end{array}$ \\
\hline
\end{tabular}

$27.3 \%$ [7] [10] [11] [20]. In a study conducted in a secondary care setting, the parent to child transmission rate was $5.2 \%$ among 154 parent-baby pairs who were fully compliant with the then existing protocol of nevirapine prohylaxis, as compared to $17.5 \%$ among non-compliant pairs [10]. In a study conducted in 33 PPTCT centers in 18 districts of Gujarat, infants who received ART for prevention were at lower risk of HIV infection than those who did not $(5.2 \%$ vs $41.1 \%$, p value $<0.0001)$ [12]. A study in West Bengal comparing the efficacy of a 
single dose versus an extended dose regimen found that the HIV transmission rate in the former group was $8.9 \%$ as compared to $10.4 \%$ in the latter group [17]. However, the difference was not statistically significant. Cumulative mortality in the extended dose regimen group was also significantly less (risk ratio $=0.53,95 \%$ CI 0.32 , 0.85) than in the single dose regimen group [17]. In a study in Maharashtra, the relative risk of acquiring HIV in infants was $0.80(\mathrm{RR}=0.80,95 \%$ C.I. 0.58 - 1.10) when given extended dose regimen as compared to a single dose regimen $[21]$.

Few studies compared the HIV transmission rate with respect to feeding patterns. A study in Maharashtra showed that infants who were exclusively formula fed had a lower transmission rate than the overall transmission rate $(3.1 \%$ vs $8.0 \%)$ [11]. Similar results were seen in studies in Gujarat where the transmission rate was $6.2 \%$ in the replacement feeding group as compared to $25.5 \%$ in the breast-feeding or mixed feeding group [12]. A study in West Bengal compared the efficacy of both perinatal nevirapine prophylaxis and feeding patterns in a single arm, and found that whereas the HIV transmission rate without any of these interventions was $57.2 \%$, it reduced to $15 \%$ in the presence of intervention with nevirapine prophylaxis and total formula feeding [15]. However, contrary results were obtained in a study in Tamil Nadu, where the HIV transmission rate among breast-fed infants was zero percent, compared to $6.5 \%$ for the entire cohort [18].

Most of the studies which compared the HIV transmission rate with respect to type of delivery showed that cesarean section was better than vaginal delivery in preventing HIV transmission. In a cohort study in Gujarat, the transmission rate in the vaginal delivery group was $4.1 \%$ as compared to $2.9 \%$ among mothers who underwent cesarean section [23]. However, one study in Maharashtra showed that cesarean section delivery was not better than vaginal delivery in reducing the HIV transmission rate [20].

The presence of concomitant chronic conditions was also found have an effect on transmission of HIV. The parent to child transmission rate among pregnant women co-infected with HIV-TB was $30 \%$, which was significantly more than the transmission rate of $12 \%$ in the absence of tuberculosis ( $p$ value $=0.02$ ) [24].

\subsection{Treatment of Children Living with HIV}

Of the 11 studies covering treatment of CLHIV, four explored levels of ART adherence, and factors associated with non-adherence to treatment; 2 examined the magnitude of loss to follow up among children on ART care, and 3 explored the effectiveness of different highly active anti-retroviral therapy (HAART) regimens in the treatment of HIV-infected children.

The attrition rate for ART among children (14 years or less) living with HIV on ART was $12.6 \%$ and $15.6 \%$ in two studies conducted in Andhra Pradesh [25] [26]. Children from the lower socio-economic group, orphans, males and younger children (aged less than two years) had a higher likelihood of attrition and thus subsequent mortality than others. Children with lower annual risk of AIDS were more likely to be lost to follow up but had less chance of mortality than others. Improvement in nutritional status was noted in terms of reduction in wasting, increase in body weight $\mathrm{z}$ score, and improvement in hemoglobin after the initiation of HAART [28] [29] [35]; Children showing an improvement in these parameters had a lower risk of subsequent mortality than others.

Appropriate adherence to ART (more than $95 \%$ of doses) varied from $65.8 \%$ to $95.5 \%$ across studies [28] [32] [34]. In a study conducted in a pediatric center for excellence for HIV care, which assessed adherence to treatment using the pill count and three-day recall period methods, appropriate adherence was more than $95 \%$. Reasons for non-adherence cited by caregivers were multiple caregivers, work constraints of the caregiver, and death or illness in the family [28]. However, a study in an ART center in Delhi reported low adherence (less than $95 \%$ of doses) in $34.4 \%$ of the children who had initiated ART. Factors associated with low adherence were low educational status of the caregiver, late initiation of ART after diagnosis, orphan status and female sex [28]. Thus, there was a considerable difference in the adherence rate in the two types of settings. One study in Tamil Nadu showed that mortality and drug resistance among children 2 - 36 months of age were higher in a nevirapine alone regimen as compared to a protease inhibitor boosted lopinavir regimen [33].

\subsection{Survival of Children Living with HIV}

Of the three studies that assessed the survival pattern of CLHIV, one study each reported time to infant diagnosis, time of entry into care and CD 4 count at the time of diagnosis as factors related to survival. CD 4 count at the time of diagnosis was an important predictor of progression of HIV [37]. Children with a baseline CD 4 
count of less than or equal to $14 \%$ had significantly higher mortality as compared to children with a CD 4 count of more than 20\% [38]. Delayed age at diagnosis had an adverse impact on the overall long-term outcome of the disease and subsequent mortality. Attrition of children diagnosed with HIV before being initiated on treatment was an important factor in the progression of the disease and subsequent mortality [36].

In a cohort study in South India, $13 \%$ of the children were lost to follow up in the one year after diagnosis. Most of the children who were not eligible for treatment during the first year were lost to follow up [37]. Children who had a delayed entry into care after ART eligibility were those diagnosed after their parent's HIV diagnosis, less than 18 months of age, female, orphan, and living more than 90 minutes from the nearest HIV center [38].

\section{Discussion}

We found that the majority of research in India has focused on the effectiveness of interventions related to nevirapine prophylaxis. However, the Government of India has decided to roll-out and scale-up the Option B plus regimen, a conclusively effective regimen [39]. However, there is a scarcity of literature related to the effectiveness of life-long ART for pregnant women in India. Our review reveals that most studies are from high HIV prevalence states of India and conducted in urban areas. Operation research covering wider geographical areas is needed since HIV among children is no longer restricted to high prevalence states [40].

The provision of exclusive formula feeding during the first six months of life is beneficial in reducing parent to child transmission of HIV. However, due to the socio-economic context in the Indian setting, consensus has been built to continue with exclusive breast-feeding during the first six months of life [41].

Most of the studies that explored issues around the treatment of CLHIV explored ART adherence and loss to follow up, and only a few studied the effectiveness of HAART. After initiating a child on ART, frequent monitoring is critical for assessing well-being as well as side effects and adherence. Monitoring should also focus on the general growth, development, immunization status as well as nutritional status. Visits should also be used as an opportunity to educate and counsel parents and care-givers on adverse drug reactions, opportunistic infections and adherence. Local evidence and operational challenges in this regard are lacking and call for adequately sampled prospective cohort studies.

Increase in accessibility to HIV treatment for the pediatric population has led to an increase in long-term survival [4]. In the present review, studies have focused mainly on outcome measures with the determinant being CD 4 count. These studies are conspicuous by being few in number and concentrated in few southern states. Factors such as access to care, socio-economic context, and tracking of children as parent-child pairs should be new areas of research, which could suggest measures to increase the survival of CLHIV and start on ART. There is a need to conduct long-term follow-up studies to explore the association between patterns and ART access in Indian settings.

Assessments are needed of the knowledge gap among the cadre of health care workers in light of new HIV treatment guidelines, implementation challenges and training needs. Evidence is also needed to improve prevention and treatment of malnutrition among HIV-exposed and HIV-infected children. Presently there is little information available on the effectiveness of nutritional interventions among HIV-infected children.

Disclosing the diagnosis of HIV to an HIV-infected child is an emotionally charged issue for parents and health care providers. The present status of research on HIV among children in India is completely missing in this regard. There have been many studies on disclosure related to patients with cancer, and lessons may be drawn for HIV [42].

\section{Conclusion}

Most of the studies included in this systematic review have been small unplanned studies, conducted as a part of routine health care delivery related to HIV. Shift in policy to provide option B regimen is yielding better results. Various factors identified as the determinants of transmission of HIV from parent to child need to be targeted. If the age at diagnosis could be reduced further, it would increase the survival of children living with HIV. The program needs to increase access to the health care facilities to improve adherence rate and reduce attrition.

\section{Recommendation}

Universalization and increased uptake of the newer and more effective Option B plus regimen is recommended. 
There is need to conduct operational research to document the effectiveness of life-long ART in pregnant women in preventing parent to child transmission of HIV in the Indian setting. Tracking of children exposed with HIV should be done as parent-child pairs, with strict follow-up. A more robust follow-up strategy should be implemented under the program. There is a need to target various modifiable programmatic factors associated with poor treatment adherence, including type of treatment setting and late initiation of ART after diagnosis. There is a need to conduct more scientifically robust studies to facilitate programmatic recommendations.

\section{Acknowledgements}

This paper (NACO/SIMU/NDAP/2015/07) was written as part of the National Data Analysis Plan (NDAP), an initiative of the Strategic Information Management Unit of National AIDS Control Organization (NACO), Ministry of Health and Family Welfare, Government of India. This project was supported by NACO's other development partners, which include Center for Diseases Control (CDC), World Health Organization-India, FHI-360, and John Snow India. This paper was conceptualized, developed and finalized by the author, under the guidance of mentors (senior public health experts) and the NDAP Unit, NACO. The Knowledge Network project of the Population Council, which is a grantee of the Bill \& Melinda Gates Foundation though Avahan, the India AIDS Initiative, has supported the scientific writing, reviewing, editing and finalization of this paper. The views expressed in this paper are those of the authors, and do not necessarily reflect the views of NACO.

\section{Authors' Contributions}

Conceived and designed the experiment: S.K., P.H., S.K.R., A.K.S. Performed the experiment: A.K.S. Wrote the paper: A.K.S., P.H. Data interpretation: S.K., P.H., S.K.R., A.K.S. Critical revision to the manuscript: S.K., P.H., S.K.R. Read and approved final manuscript: S.K., P.H., S.K.R., A.K.S. Guarantor of the paper: P.H., A.K.S.

\section{References}

[1] National AIDS Control Organisation (2015) Annual Report 2013-2014. Department of AIDS Control Ministry of Health and Family Welfare Government of India, New Delhi.

[2] Pandey, A., Sahu, D., Bakkali, T., Reddy, D., Venkatesh, S. and Kant, S. (2012) Estimate of HIV Prevalence and Number of People Living with HIV in India 2008-2009. BMJ Open, 2, 5. http://dx.doi.org/10.1136/bmjopen-2012-000926

[3] National AIDS Control Organisation (2013) Updated Guidelines for Prevention of Parent to Child Transmission (PPTCT) of HIV Using Multi Drug Ante Retroviral Regimen in India. http://naco.gov.in/NACO/Quick_Links/Publication/Basic_Services/National_Guidelines_for_PPTCT/National_Guideli nes_for_Prevention_of_Parent_to_Child_Transmission_PPTCT_of_HIV2/

[4] UNAIDS (2013) UNAIDS Report on the Global AIDS Epidemic. http://www.unaids.org/en/resources/documents/2013/20130923_UNAIDS_Global_Report_2013

[5] World Health Organization (2013) Consolidated Guidelines on the Use of Anteretroviral Drugs for Treating and Preventing HIV Infection. http://www.who.int/hiv/pub/guidelines/arv2013/en/

[6] Darak, S., Panditrao, M., Parchure, R., Kulkarni, V., Kulkarni, S. and Janssen, F. (2012) Systematic Review of Public Health Research on Prevention of Mother-to-Child Transmission of HIV in India with Focus on Provision and Utilization of Cascade of PMTCT Services. BMC Public Health, 12, 320. http://dx.doi.org/10.1186/1471-2458-12-320

[7] Alvarez-Uria, G., Midde, M., Pakam, R., Bachu, L. and Naik, P.K. (2012) Effect of Formula Feeding and Breastfeeding on Child Growth, Infant Mortality, and HIV Transmission in Children Born to HIV-Infected Pregnant Women Who Received Triple Antiretroviral Therapy in a Resource-Limited Setting: Data from an HIV Cohort Study in India. ISRN Pediatr, 2012, Article ID: 763591. http://dx.doi.org/10.5402/2012/763591

[8] Arora, D., Gupta, R.M. and Kochar, S.P.S. (2014) Efficacy of Single Dose Nevirapine in Reducing Viral Load in HIV Positive Mother in Labour and Transmission of HIV Infection to New Born Babies as Part of Prevention of Parent to Child Transmission. Medical Journal Armed Forces India, 70, 309-314. http://dx.doi.org/10.1016/j.mjafi.2014.09.005

[9] Goswami, S. and Chakravorty, P.S. (2011) Prevention of Parent to Child Transmission of HIV (PPTCT): An Effort of 4 Years in a Tertiary Centre. The Journal of Obstetrics and Gynecology of India, 61, 394-398. http://dx.doi.org/10.1007/s13224-011-0056-1

[10] Gupta, R., Praveen, R. and Sharma, M. (2013) Can We Prevent Pediatric HIV? An Experience at a Tertiary Care Hos- 
pital. Medical Journal Armed Forces India, 69, 218-221. http://dx.doi.org/10.1016/j.mjafi.2012.11.008

[11] Gupta, A., Gupte, N., Sastry, J., Bharucha, K.E., Bhosale, R., Kulkarni, P., et al. (2007) Mother-to-Child Transmission of HIV among Women Who Chose Not to Exclusively Breastfeed Their Infants in Pune, India. Indian Journal of Medical Research, 126, 131-134.

[12] Jain, K.K., Mahajan, R.K., Shevkani, M. and Kumar, P. (2011) Early Infant Diagnosis: A New Tool of HIV Diagnosis in Children. Indian Journal of Community Medicine, 36, 139-142. http://dx.doi.org/10.4103/0970-0218.84134

[13] Joshi, U., Patel, S., Shah, K., Oza, U. and Modi, H. (2011) Studying PPTCT Services, Interventions, Coverage and Utilization in India. Journal of Global Infectious Diseases, 3, 371-377. http://dx.doi.org/10.4103/0974-777X.91062

[14] Joshi, U., Kadri, A. and Bhojiya, S. (2010) Prevention of Parent to Child Transmission Services and InterventionsCoverage and Utilization: A Cohort Analysis in Gujarat, India. Indian Journal of Sexually Transmitted Diseases and AIDS, 31, 92-98. http://dx.doi.org/10.4103/0253-7184.74983

[15] Mandal, S., Bhattacharya, R.N., Chakraborty, M., Pal, P.P., Roy, S.G. and Mukherjee, G. (2010) Evaluation of the Prevention of Parent to Child Transmission Program in a Rural Tertiary Care Hospital of West Bengal, India. Indian Journal of Community Medicine, 35, 491-494. http://dx.doi.org/10.4103/0970-0218.74352

[16] Merchant, R.H., Damania, K., Gilada, I.S., Bhagwat, R.V., Karkare, J.S., Oswal, J.S., et al. (2001) Strategy for Preventing Vertical Transmission of HIV: Bombay Experience. Indian Pediatrics, 38, 132-138.

[17] Omer, S.B., Six Week Extended Dose Nevirapine (SWEN) Study Team (2011) Twelve-Month Follow-Up of Six Week Extended Dose Nevirapine Randomized Controlled Trials: Differential Impact of Extended-Dose Nevirapine on Mother-to-Child Transmission and Infant Death by Maternal CD4 Cell Count. AIDS, 25, 767-776. http://dx.doi.org/10.1097/QAD.0b013e328344c12a

[18] Read, J.S., Samuel, N.M., Srijayanth, P., Dharmarajan, S., Van Hook, H.M., Jacob, M., et al. (2010) Infants of Human Immunodeficiency Virus Type 1-Infected Women in Rural South India: Feeding Patterns and Risk of Mother-to-Child Transmission. The Pediatric Infectious Disease Journal, 29, 14-17. http://dx.doi.org/10.1097/INF.0b013e3181b20ffc

[19] Seth, A., Gupta, R., Chandra, J., Maheshwari, A., Kumar, P. and Aneja, S. (2014) Adherence to Antiretroviral Therapy and Its Determinants in Children with HIV Infection-Experience from Paediatric Centre of Excellence in HIV Care in North India. AIDS Care, 26, 865-871. http://dx.doi.org/10.1080/09540121.2013.859649

[20] Shah, I. (2006) Is Elective Caesarian Section Really Essential for Prevention of Mother to Child Transmission of HIV in the Era of Antiretroviral Therapy and Abstinence of Breast Feeding? Journal of Tropical Pediatrics, 52, 163-165. http://dx.doi.org/10.1093/tropej/fml014

[21] Six Week Extended-Dose Nevirapine (SWEN) Study Team, Bedri, A., Gudetta, B., Isehak, A., Kumbi, S., Lulseged, S., et al. (2008) Extended-Dose Nevirapine to 6 Weeks of Age for Infants to Prevent HIV Transmission via Breastfeeding in Ethiopia, India, and Uganda: An Analysis of Three Randomized Controlled Trials. The Lancet, 372, 300-313.

[22] Chaudhuri, S., Mundle, M., Konar, H., Das, C., Talukdar, A. and Ghosh, U.S. (2010) Utilization of Therapeutic Intervention to Prevent Mother to Child Transmission of HIV in a Teaching Hospital in Kolkata, India. Journal of Obstetrics and Gynaecology Research, 36, 619-625. http://dx.doi.org/10.1111/j.1447-0756.2009.01161.x

[23] Ahir, S.P., Chavan, V., Kerkar, S., Samant-Mavani, P., Nanavati, R., Mehta, P.R., et al. (2013) Antiretroviral Treatment, Viral Load of Mothers \& Perinatal HIV Transmission in Mumbai, India. Indian Journal of Medical Research, 138, 201-208.

[24] Gupta, A., Bhosale, R., Kinikar, A., Gupte, N., Bharadwaj, R., Kagal, A., et al. (2011) Maternal Tuberculosis: A Risk Factor for Mother-to-Child Transmission of Human Immunodeficiency Virus. Journal of Infectious Diseases, 203, 358-363. http://dx.doi.org/10.1093/jinfdis/jiq064

[25] Alvarez-Uria, G., Naik, P.K., Midde, M. and Pakam, R. (2013) Predictors of Delayed Entry into Medical Care of Children Diagnosed with HIV Infection: Data from an HIV Cohort Study in India. Scientific World Journal, 2013, Article ID: 737620.

[26] Alvarez-Uria, G., Naik, P.K., Midde, M. and Pakam, R. (2014) Predictors of Loss to Follow-Up after Engagement in Care of HIV-Infected Children Ineligible for Antiretroviral Therapy in an HIV Cohort Study in India. Germs, 4, 9-15. http://dx.doi.org/10.11599/germs.2014.1049

[27] Banerjee, T., Pensi, T., Banerjee, D. and Grover, G. (2010) Impact of HAART on Survival, Weight Gain and Resting Energy Expenditure in HIV-1-Infected Children in India. Annals of Tropical Paediatrics, 30, $27-37$. http://dx.doi.org/10.1179/146532810X12637745451915

[28] Bhattacharya, M. and Dubey, A.P. (2011) Adherence to Antiretroviral Therapy and Its Correlates among HIV-Infected Children at an HIV Clinic in New Delhi. Annals of Tropical Paediatrics, 31, 331-337. http://dx.doi.org/10.1179/1465328111Y.0000000031

[29] Bhattacharya, M. and Saxena, R. (2012) Outcome of Anti-Retroviral Treatment in HIV-Infected Orphans and NonOrphans at an ART Centre in North India. Paediatrics and International Child Health, 32, 228-232. 
http://dx.doi.org/10.1179/2046905512Y.0000000035

[30] Choudhary, N., Gomber, S. and Narang, M. (2012) Clinico-Immunological Profile and Outcome of Antiretroviral Therapy in HIV-Positive Children. Public Health Nutrition, 15, 1442-1445. http://dx.doi.org/10.1017/S1368980011003181

[31] Gomber, S., Kaushik, J.S., Chandra, J. and Anand, R. (2011) Profile of HIV Infected Children from Delhi and Their Response to Antiretroviral Treatment. Indian Pediatrics, 48, 703-707. http://dx.doi.org/10.1007/s13312-011-0117-7

[32] Seth, A., Chandra, J., Gupta, R., Kumar, P., Aggarwal, V. and Dutta, A. (2012) Outcome of HIV Exposed Infants: Experience of a Regional Pediatric Center for HIV in North India. Indian Journal of Pediatrics, 79, 188-193.

[33] Violari, A., Lindsey, J.C., Hughes, M.D., Mujuru, H.A., Barlow-Mosha, L., Kamthunzi, P., et al. (2012) Nevirapine versus Ritonavir-Boosted Lopinavir for HIV-Infected Children. The New England Journal of Medicine, 366, 23802389. http://dx.doi.org/10.1056/NEJMoa1113249

[34] De, A.K. and Dalui, A. (2012) Assessment of Factors Influencing Adherence to Anti-Retroviral Therapy for Human Immunodeficiency Virus Positive Mothers and Their Infected Children. Indian Journal of Medical Sciences, 66, 247259. http://dx.doi.org/10.4103/0019-5359.115733

[35] Rajasekaran, S., Jeyaseelan, L., Ravichandran, N., Gomathi, C., Thara, F. and Chandrasekar, C. (2009) Efficacy of Antiretroviral Therapy Program in Children in India: Prognostic Factors and Survival Analysis. Journal of Tropical Pediatrics, 55, 225-232. http://dx.doi.org/10.1093/tropej/fmm073

[36] Alvarez-Uria, G., Naik, P.K., Midde, M. and Pakam, R. (2014) Mortality and Loss to Follow up before Initiation of Antiretroviral Therapy among HIV-Infected Children Eligible for HIV Treatment. Infectious Disease Reports, 6, 5167.

[37] Gupta, A., Singh, G., Kaushik, P., Joshi, B., Kalra, K. and Chakraborty, S. (2013) Early Diagnosis of HIV in Children below 18 Months Using DNA PCR Test-Assessment of the Effectiveness of PMTCT Interventions and Challenges in Early Initiation of ART in a Resource-Limited Setting. Journal of Tropical Pediatrics, 59, 120-126. http://dx.doi.org/10.1093/tropej/fms063

[38] Radhakrishna, M., Durga, K., Rao, R.K., Reddy, D.M. and Kondapi, A.K. (2013) Factors Associated with Conversion of Long-Term Non-Progressors to Progressors: A Prospective Study of HIV Perinatally Infected Pediatric Survivors. Indian Journal of Medical Research, 138, 322-328.

[39] Department of AIDS Control, Ministry of Health and Family Welfare, Government of India (2013) National Strategic Plan; Multi Drug ARV for Prevention of Parent to Child Transmission of HIV (PPTCT) under National AIDS Control Programme in India.

[40] Department of AIDS Control, Ministry of Health and Family Welfare, Government of India (2014) Assessment of Parent to Child Transmission of HIV (PPTCT) Services Implementation in India.

[41] Department of AIDS Control, Ministry of Health and Family Welfare, Government of India (2013) Nutritional Guidelines for HIV Exposed and Infected Children (0-14 Years of Age).

[42] Badarau, D.O., Wangmo, T., Ruhe, K.M., Miron, I., Colita, A., Dragomir, M., Schildmann, J. and Elger, B.S. (2015) Parents' Challenges and Physicians' Tasks in Disclosing Cancer to Children. A Qualitative Interview Study and Reflections on Professional Duties in Pediatric Oncology. Pediatric Blood \& Cancer. (In Press) http://dx.doi.org/10.1002/pbc.25680 